ENTORNOS, No. 27. | Abril 2014

ARTÍCULO DE INVESTIGACIÓN

Recibido: 4 Febrero / Recibido en forma revisada: 5 Marzo / Aceptado: 12 Abril

\title{
Uso ideológico del lenguaje en el discurso informativo de la prensa escrita. Caso Colombia
}

\section{Ideological language use in the informative speech of written press. A Colombian Case.}

\section{Ideologischer gebrauch von sprache im informativen diskurs der presse: Der Fall Kolumbien}

Freddy Alberto Mier Logato

Magister en Lingüística. Universidad Surcolombiana. Neiva. Colombia freddy.mier@hotmail.com

\section{Resumen}

Se afirma con frecuencia que los medios informativos mienten, tergiversan los hechos y orientan la información hacia intereses acordes con su filosofía. El presente trabajo intenta demostrar que el discurso informativo de la prensa escrita (que en la superficie se formaliza como un texto noticioso-expositivo cuya misión es informar) puede funcionaren el fondo como modalidad argumentativa con la que se asumen posiciones ideológicas. El objetivo es mostrar, desde el Análisis Crítico del Discurso, cómo la prensa escrita, utilizando los espacios informativos, manifiesta subrepticiamente una posición política y emprende acciones estratégicas encubiertas con el fin de orientar la información hacia la deslegitimación de posiciones ideológicas contrarias o que no le favorecen. Es lo que en este trabajo se denomina usoideológico del lenguaje. Para llevar a cabo el análisis discursivo se escogieron dos textos informativos publicados en El Tiempo, diario de mayor circulación en Colombia. Los textos corresponden al registro de dos marchas que se realizaron en este país, una contra la guerrilla de las FARC y otra contra los grupos paramilitares. Los resultados de este trabajo muestran que el discurso informativo de la prensa no puede ser objetivo, neutral, equilibrado e imparcial por cuanto la enunciación discursiva se realiza desde instituciones inmersas en condiciones de poder y dominación.

Palabras clave: Uso ideológico del lenguaje, discurso informativo de la prensa, Análisis Crítico del Discurso.

\begin{abstract}
It is often said that informative media lies, misrepresent the facts and lead the information to beliefs that are in accordance to their philosophy. This research tries to demonstrate that the informative speech of written press (that in the surface formalizes as a expositive-news text which misión is to inform) can work in depth as an argumentative pattern in which ideological positions are assumed. The goal is to show, from the Critical Speech Analysis, how the written press, using the informative fields, surreptitiously expresses a political stand and launches undercover strategic actions with the goal of guiding the information towards the un-legitimize of contrary ideological stands or the ones that doesnt favor them. Is what in this research is named language ideologic use.

To carry out the speech analysis two informative texts were chosen, these were published in El Tiempo newspaper, the largest circulation newspaper in Colombia. The texts belong to the registering of two stikes marchs that were done in this country, one against the FARC guerilla and the other against the Paramilitary groups. The results of this research show that the informative speech cant be objective, neutral, balanced and impartial given that speech establishment is done from institutions that are immersed in power and domination conditions.
\end{abstract}

Keywords: Ideological use of language, Informative Press speech, Critical Speech Analysis.

\section{Zusammenfassung}

Es wird immer wieder behauptet, dass die informativen Medien lügen, die Tatsachen verdrehen und die Informationen so übermitteln, dass sie mit ihrer Philosophie übereinstimmen. Die vorliegende Arbeit beabsichtigt zu zeigen, dass der informative Diskurs der Presse (der sich an der Oberfläche als nachrichtlichunterrichtender Text zeigt, dessen Mission es ist, zu informieren) im Grunde in einer argumentativen Weise funktionieren kann, mit der ideologische Positionen übernommen werden. Das Ziel ist es, durch die Kritische Analyse des Diskurses zu zeigen, wie die geschriebene Presse mittels der informativen Flächen heimlich eine politische Position manifestiert und verdeckte strategische Aktionen unternimmt, mit der Absicht, die 
Informationen durch die Diskreditierung konträrer ideologischer Positionen oder solcher Positionen, die sie nicht unterstützt, in eine bestimmte Richtung zu lenken. In der vorliegenden Arbeit wird dies als Ideologischer Gebrauch von Sprache bezeichnet. Zur Durchführung der diskursiven Analyse wurden zwei informative Texte ausgewăhlt, die in El Tiempo, der Tageszeitung mit der größten Reichweite in Kolumbien, erschienen sind. Die Texte entsprechen der Anmeldung zweier Märsche, die in diesem Land durchgeführt wurden, einer gegen die Guerilla der FARC und der andere gegen die paramilitärischen Gruppen. Das Ergebnis dieser Arbeit zeigt, dass der informative Diskurs der Presse nicht objektiv, neutral, ausgewogen oder unparteiisch sein kann, weil die diskursive Mitteilung von Institutionen gelenkt wurde, die in Macht- und Herrschaftsverhältnisse verwickelt sind.

\section{Introducción}

En un mundo como el nuestro, en el que cobran fuerza la ficción, la falsedad, el engaño y la manipulación, los grandes medios informativos desempeñan un papel fundamental en la forma como piensa, actúa y se comporta la sociedad. Puede afirmarse que el criterio para el análisis de los hechos, de alguna manera se sustenta en el registro que los medios informativos hacen de la realidad.

En este trabajo se afirma que el lenguaje usado en el discurso informativo de la prensa puede tener una orientación ideológica, por cuanto sus condiciones de producción se emparentan con relaciones de poder y dominación. En este sentido, la organización de los elementos lingüísticos y no lingüísticos de este discurso va acorde con la ideología y los intereses de una clase socio-política a la que le interesa mostrar que la información presentada en sus medios hace honor a la imparcialidad, el equilibrio, la objetividad y la neutralidad ${ }^{1}$. Es tarea del analista demostrar que el discurso informativo de la prensa en ocasiones enmascara sus intereses haciendo uso de lo que Habermas llama acción estratégica encubierta, toda vez que hay un engaño consciente y deliberado, "simulando un cumplimiento de las condiciones de la acción comunicativa" (Habermas, 1997, 386).

Conviene aclarar qué se entiende en este trabajo como ideología. Aquí la entendemos como la visión particular o colectiva de una persona o de un grupo social que tiene una determinada forma de concebir el mundo y de concebir las relaciones sociales. Para van Dijk (2005, 54), las ideologías "representan los principios subyacentes de la cognición social y, de ese modo, forman la base del conocimiento, de las actitudes y de otras creencias más específicas compartidas por un grupo". No se toma en el sentido de "bueno", "malo", "falso" o "verdadero". Lo que sucede es que las ideologías de los grupos sociales inmersos en condiciones de poder manejan a su antojo la forma de ver el mundo de los grupos minoritarios y carentes de poder. Es decir, les imponen una forma de ver y de asumir la realidad, incluso contra ellos mismos.

Con el fin de mostrar que en ocasiones existe un proceso de argumentación en el nivel más profundo de los textos noticioso-expositivos, se analizan dos noticias publicadas en El Tiempo, diario de mayor circulación en Colombia. Los textos registran dos marchas que se realizaron en este país, una en rechazo al grupo guerrillero FARC (de extrema izquierda) y otra en rechazo a los grupos paramilitares (de extrema derecha).

El análisis se inicia con un marco referencial que define el discurso informativo y presenta como soporte el Análisis Crítico del Discurso (ACD), interdisciplina que asume posiciones en sus análisis. El trabajo muestra unos resultados específicos y plantea una discusión en torno al papel fundamental de los medios que, al registrar los hechos, muchas veces tienden a la manipulación, la mentira y el engaño.

\section{Marco referencial}

\section{Consideraciones sobre el discurso informativo de la prensa}

Se entiende el discurso informativo, en general, como un tipo de discurso que transmite información de manera referencial, directa, precisa, concreta y fiel sobre el mundo objetivo. En este sentido, el discurso informativo supone un alejamiento emotivo del yo sobre el qué que se transmite como información. Sobra decir que en el discurso informativo se le da prioridad a un hecho del mundo real sin que medie la valoración del sujeto que enuncia. La distancia que se toma del referente evocado se formaliza a través del uso de la tercera persona, del modo verbal indicativo y de oraciones impersonales.

1 - Es necesario distinguir estos cuatro conceptos en el manejo de la información. La imparcialidad tiene que ver con el hecho de no tomar partido explícitamente a favor o en contra de algo. El equilibrio se refiere a la distribución igualitaria de la información cuando se trata de presentar posiciones contrarias. La objetividad se refiere a la transmisión de los hechos tal como han sucedido. La neutralidad se refiere al sentir del sujeto, a su fuero interno. La imparcialidad y el equilibrio, referidos a la información, son posibles de alcanzar. La objetividad, aplicada a la transmisión de un hecho noticioso, es imposible de alcanzar por cuanto los hechos nunca se transmiten tal como han sucedido: llegan "contaminados" por la visión del informador. La neutralidad no existe: las personas siempre asumen posiciones. 
Aplicadas estas consideraciones al discurso informativo de la prensa podríamos decir que éste debería caracterizarse por presentar los hechos del mundo real de manera veraz, imparcial y equilibrada, sin que la posición ideológica del medio incida sobre la información que se transmite. Se espera que un medio en una sociedad democrática brinde a sus receptores información fidedigna, teniendo en cuenta que el acceso a ella es un derecho inalienable.

No obstante, se ha demostrado a través de numerosos análisis que el discurso informativo de la prensa puede esconder intereses particulares, por una razón fundamental: su estructura proviene de sectores sociopolíticos inmersos en condiciones de poder desde donde se configura al tú receptor, incluso sin que éste sospeche que ha sido "configurado". Quien realiza la emisión en el discurso informativo de la prensa no sólo se encuentra en libertad de escoger el objeto sobre el cual hablará, de presentar ese referente desde su perspectiva, sino que tiene también la facultad de convertirse en un yo encubierto. Así, el enunciador puede dirigir, orientar y acomodar la cadena significante del discurso hacia las condiciones que le favorecen al medio, dejando al receptor en condiciones de vulnerabilidad, pues la configuración de éste depende de la visión que el emisor tenga de él ${ }^{2}$.

En el discurso informativo de la prensa el enunciador asume una manera de ser del otro: lo que se organiza en la cadena discursiva es lo que el locutor considera que el receptor debe conocer. Este emisor conoce y entiende las condiciones socio-políticas y culturales en que se encuentra ese receptor y organiza su discurso con el propósito oculto de que asuma ciertas posiciones. Bien lo dicen Costa y Mozejko $(2001,30)$ a propósito de la forma como se ubican en el discurso el enunciador y el enunciatario:

Todo enunciado es un objeto que circula entre dos sujetos: el yo se instaura a sí mismo y, simultánea-mente, construye al túenunciatario, como simulacro cuyas marcas registra el enunciado. Este simulacro del receptor no corresponde necesariamente a la figura de un sujeto cooperador; más bien, la serie de estrategias tendientes a persuadirlo corrobora la hipótesis del conflicto, la posibilidad de que las significaciones propuestas sean aceptadas orechazadas por el enunciatario.

Teniendo en cuenta lo que dicen estos autores sobre la ventaja que tiene el yo-enunciador en todo proceso de enunciación, podemos decir que en el discurso informativo de la prensa ese enunciador se ubica en condiciones privilegiadas de poder porque tiene la facultad de dirigir la cadena discursiva y de configurar al tú enunciatario, no como un sujeto cooperador, sino como simulacro con el fin de que actúe y piense como él considera que debe hacerlo.

\section{Los medios informativos}

Se dice que la prensa constituye un cuarto poder. No obstante, si revisamos con cuidado esta afirmación, encontramos que los demás poderes (económico, político, militar y religioso) se nutren, legitiman y tienen su razón de ser en los medios masivos de información, a través de los cuales un sector privilegiado de la sociedad orienta y dirige normas de comportamiento, formas de interpretar la realidad, creencias y posiciones políticas e ideológicas que le favorecen $^{3}$. No es cierto que los medios informativos detenten un poder "autónomo" e independiente que hace contrapoder: ellos son la expresión "natural" de los demás poderes. Que la prensa constituye un poder debe entenderse en el sentido de que es tal su influencia, que aquellas realidades que no están informatizadas se considera que "no existen", y si existen "no son legítimas". Pero no debe entenderse su poder en el sentido de contrapoder: los dueños de los grandes medios son grupos económicos que no sólo controlan las telecomunicaciones, sino también los demás sectores: político, financiero, industrial, etc.

Si los medios pertenecen a grupos económicos, es una utopía pretender que sean imparciales, objetivos, equilibrados y neutrales ante lo que informan. Es más, en una sana democracia los medios informativos deben asumir posiciones políticas sobre la realidad (en ese sentido no se les puede pedir que sean neutrales) y no ser meras cajas de resonancia de lo que acontece. El hecho de que en sus editoriales asuman posiciones a favor o en contra de determinadas causas (es decir, que estén parcializados) no debe ser motivo de demonización. Lo inaceptable es que los medios, recurriendo a la manipulación, utilicen los espacios informáticos para presentar sus intereses con el fin de que todos los acepten como verdad.

Se ha llegado a considerar que la objetividad, en lo que tiene que ver con la transmisión de la información, es imposible de alcanzar porque quien emite recurre a su esquema cognitivo, el cual, por supuesto, corresponde al de un individuo que piensa, siente y ve el mundo de una manera particular. No obstante, aunque se comparta en gran medida esta consideración, un medio periodístico debe buscar ecuanimidad en el manejo de la información. Si bien un medio no puede ser neutral ni objetivo en lo que plantea en sus editoriales, sí puede buscar la imparcialidad y el equilibrio en los textos informativos.

2 - En el discurso de la prensa el locutor anula toda posición crítica del "interlocutor". Por ejemplo, en la sección Carta de los lectores, los diarios se reservan el derecho de publicarlas o de suprimir apartados. Asimismo, en las versiones On line se suprimen comentarios que no favorecen la posición del medio.

3 - Se entiende en este trabajo poder como lo concibe van Dijk, es decir, como control: "El concepto explicativo que utilizamos para definir el poder social es el de control. Un grupo tiene poder sobre otro si tiene alguna forma de control sobre ese otro grupo. Más específicamente, un control de este tipo puede aplicarse a las acciones de (los miembros de) el otro grupo: controlamos a los otros si podemos hacer que actúen como deseamos (o impedir que actúen en contra nuestra)". (van Dijk, 2005, 40). 
El porqué de un análisis crítico sobre el discurso informativo de la prensa

Esta sociedad se alimenta de la información masiva, y quien lea a diario la prensa puede ufanarse de estar informado. No obstante, los análisis de registros noticiosos han demostrado que los medios informativos pueden utilizar el lenguaje con el fin de desinformar, máxime cuando el lenguaje puede convertirse en un medio de dominación.

Como en estos tiempos se volvió un lugar común afirmar que la prensa no es objetiva, imparcial ni equilibrada, la tarea nuestra, desde el análisis crítico del uso del lenguaje, es poder mostrar cómo se presenta la manipulación en textos aparentemente expositivo-informativos. De esta forma estaríamos contribuyendo a la construcción de una sociedad instruída sobre cómo detectar la manipulación en el manejo de la información. Estaríamos creando un "quinto poder": el de la sociedad civil ilustrada que hace contrapeso a la prensa oficial ${ }^{4}$.

Teniendo en cuenta que en el discurso informativo puede hacerse un uso ideológico del lenguaje, algunos medios utilizan mecanismos para tergiversar la información. Es tan sutil e imperceptible la manipulación, que en ocasiones pasa desapercibida. Cuando se les reclama a los medios por el manejo indebido que le dan a determinada situación, se excusan diciendo que se trata de errores "involuntarios". Veamos, grosso modo, algunos de esos mecanismos que pueden utilizarse para manipular.

\section{La página titular}

La página titular de un diario es un espejo en el que se "refleja" la realidad de un país o de una sociedad, pues en ella se resaltan los acontecimientos más importantes. No obstante, la escogencia de las noticias que van en la página titular la hace el editor con criterios personales o institucionales. Hay editores que prefieren publicar la imagen de un reinado de belleza y no la de una masacre con el pretexto de no proyectar una imagen "negativa" o "pesimista" de la sociedad que influya en el inconsciente colectivo. Sin embargo, hay ocasiones en que se magnifica un hecho con el propósito de desviar la atención de un tema de mayor trascendencia en el momento, pero que no es del agrado del medio o no corresponde con sus intereses (algunos llaman "cortina de humo" a estas acciones estratégicas encubiertas).

\section{Los títulos entrecomillados}

Muchos titulares se entrecomillan para indicar que se tomaron de frases textuales. Unas comillas le dan fuerza a un titular, pues se pone a hablar a uno de los actantes. Sin embargo, esta forma de construír el titular puede ser tendenciosa porque: i) La frase queda fuera de contexto en el titular, y eso puede tergiversar el propósito informativo de quien enuncia; ii) La frase entre comillas muchas veces no se toma textualmente de lo que alguien dijo, sino que se construye con las ideas del redactor. En este caso se trata de poner en boca de una persona lo que ella no dijo o no quiso decir de esa manera; iii) Entre tantas emisiones de los actantes en el texto informativo, el redactor destaca UNA: la que le conviene al medio informativo. Verbigracia, en este titular: "Paro de pilotos sería un suicidio", dijo director de la Aeronáutica Civil se dejan de lado otros aspectos (por ejemplo, las razones que llevaron a los pilotos a votar la huelga) con el fin de hacer énfasis en que si los pilotos paran, se estarían "suicidando" laboralmente, pues la empresa quebraría.

\section{Información vs. Publicidad}

En ocasiones no se precisa una distinción entre información y publicidad, y el receptor del mensaje puede ser manipulado. Por ejemplo, en un programa radial de Colombia una reconocida psicóloga presentaba un cuadro clínico de la depresión y la forma como se manifiesta. Y concluía la psicóloga: "Para abordar este tema hemos invitado a la doctora $X$ que nos va a hablar de un nuevo producto contra la depresión llamado X". En este caso, ¿es creíble una información cuando hay intereses comerciales de por medio?

Por otra parte, hay grupos económicos que aprovechan sus medios informativos para dar a conocer supuestas noticias que, de manera oculta, benefician la venta de uno de sus productos. En un noticiero televisual colombiano un día titularon: "Se ha demostrado que el consumo de cerveza, en cantidad moderada, es bueno para la salud". Y en el desarrollo de la "noticla" aparecían unos hombres de bata blanca en un laboratorio (la autoridad, la investidura) afirmando que el consumo de dos cervezas diarias es bueno para la salud. Podríamos creer que tal afirmación es cierta si no supiéramos que el canal pertenece a un grupo económico que es dueño de la cervecería más grande del país. Bien lo dice Ignacio Ramonet (2004):

Estos grupos ahora son los grandes poderes. Ellos promocionan como noticia lo que sus empresas hacen. Su preocupación es el beneficio y no la calidad de la información. En los últimos años se ha degradado esta calidad: se difunden notas sin edición apropiada ni profundidad, se minimiza al periodista frente a las agencias de prensa, se reduce personal y se trabaja más. No hay preocupación cívica. No se defiende a los sin voz. Ahora se vende. El medio es un poder que oprime al ciudadano, lo vende y lo banaliza. No es un contrapoder.

\section{La sección}

La escogencia de la sección para registrar un hecho noticioso puede tener un manejo ideológico. Por ejemplo, si la acusación de corrupción contra un

4 - Ver Ramonet (2004).

5 - Las comillas indican que no siempre los medios reflejan la realidad, pues el periódico es el que decide qué es noticia y qué no. Mientras un diario resalta la imagen de un futbolista luciendo su nueva camiseta, otro le da prioridad a la imagen de una población arrasada por un sismo. 
ministro por compra de votos aparece en la sección Política y no en Judiciales, puede inferirse que este caso es tratado en ese medio como "persecución política" y no como delito.

\section{Ignorar la posición contraria}

En la presentación de un hecho noticioso (por ejemplo, acuerdo del salario mínimo entre sindicalistas y gobierno), es frecuente que se tome como fuente a una de las partes implicadas y se ignoren la opinión y los argumentos de la otra. En este caso hay desequilibrio y parcialidad, de acuerdo a los intereses que haya de por medio. Ignorar las posiciones contrarias es una estrategia muy común.

\section{Imagen y texto}

En ocasiones las imágenes que acompañan un texto pueden darle otro sentido al contenido de la información. También sucede lo contrario: que un texto (pie de foto, por ejemplo) no corresponde con la realidad de la imagen que describe. No obstante, el redactor busca crear una relación "directa" y "natural" entre el texto y la imagen.

El analista de medios, Germán Rey, en su papel de Defensor del Lector de El Tiempo, cuenta que una ciudadana reclamó al diario porque la foto de una familiar suya aparecía en muletas, acompañada de un titular que rezaba más o menos así: Las víctimas de la guerra. El problema de la niña que aparecía en la fotografía no tenía relación alguna con el conflicto, pues había sufrido una enfermedad que la dejó discapacitada. El periódico sacó la foto del archivo, sin investigar su procedencia, olvidando que:

...la imagen puesta en un medio de comunicación es un acto público de exposición, una declaración social que no deja de tener riesgos. Una fotografía no es simplemente una imagen. Es un compendio de historia, memoria, personalidad. Un encuentro del mundo del pasado con las aspiraciones de futuro. (Rey, 2000).

Las anteriores estrategias son formas de lenguaje que los medios informativos pueden utilizar para manipular la información. Bien lo dice Charaudeau $(2003,15)$ :

La información es esencialmente una cuestión de lenguaje, y el lenguaje no es transparente; presenta su propia opacidad mediante la cual se construye una visión y un sentido particular del mundo.

El ACD como herramienta de análisis del discurso informativo

Conviene hacer este análisis a la luz de los planteamientos del ACD, interdisciplina que se ha preocupado en los últimos años por el poder y la ideología que circulan en los discursos, ante todo cuando provienen de sectores de la sociedad inmersos en condiciones de poder desde las que pueden influir tácita o explícitamente en la forma de pensar de las mayorías. Para van Dijk (1999) el ACD:

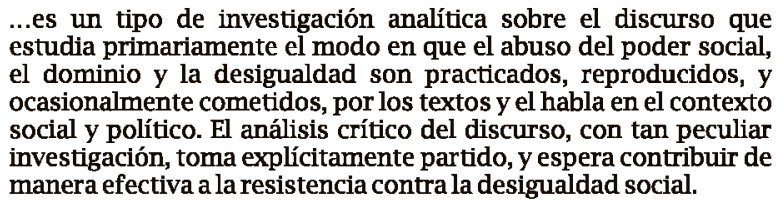

Como dice van Dijk, el ACD "intenta contribuir a dotar de poder a quienes carecen de él, con el fin de ampliar el marco de la justicia y de la igualdad sociales" (van Dijk, 1999). Por eso mismo, pierde importancia este tipo de análisis si no se dirige a aquellos sectores que carecen de herramientas cognitivas para enfrentar la manipulación.

Wodak (2003) plantea que el ACD tiene los siguientes propósitos y preocupaciones:

- Analizar en forma crítica el lenguaje de quienes detentan el poder.

- Estudiar el lenguaje como práctica social que se da en contextos determinados.

- Estudiar los problemas sociales y su relación con el uso del lenguaje.

- Desmitificar los discursos que provienen del poder y descifrar sus ideologías.

- Investigar de forma crítica la desigualdad social, expresada en los usos del lenguaje.

Meyer (2003, 36) también plantea que el ACD:

...sigue un enfoque diferente y crítico frente a los problemas, ya que se esfuerza por hacer explícitas las relaciones de poder que con frecuencia se hallan ocultas, y por consiguiente, se afana en extraer resultados que tengan alguna relevancia práctica.

Así, en este trabajo se considera el ACD como una herramienta valiosa en el análisis del discurso informativo de la prensa, teniendo en cuenta que este discurso se produce en instituciones inmersas en condiciones de dominación (grandes grupos económicos).

\section{Los Registros Noticiosos}

A continuación se presenta el registro que el diario $E l$ Tiempo hizo de dos marchas que se realizaron en Colombia en 2008. La promoción de las marchas no tuvo el mismo eco en los medios de comunicación, lo que se tradujo en el resultado: una marcha muy nutrida (la del 4 de febrero, contra la guerrilla de las FARC) y otra, menos concurrida (la del 6 de marzo, contra los paramilitares) ${ }^{6}$. Se presentan los dos textos y luego se hacen observaciones y análisis sobre la forma como se registran las marchas.

Marcha del 4 de febrero contra la guerrilla de las FARC

Un grupo de jóvenes usuarios de Facebook convocó a una marcha contra la guerrilla de las FARC (Fuerzas

6 - Estas marchas se convirtieron en símbolo de rechazo a los grupos violentos en Colombia. He aquí una reseña de ellas: http://es.wikipedia.org/wiki/Un_mill\%C3\%B3n_de_voces_contra_las_FARC 
Armadas Revolucionarias de Colombia), para que dejara en libertad a los secuestrados. La convocatoria tuvo eco en distintos medios nacionales e internacionales.

\section{Contexto socio-político en que se produce el texto noticioso de análisis}

En Colombia se vive un conflicto armado desde hace varias décadas, donde confrontan guerrilleros, paramilitares y miembros de la Fuerza Pública. Los grupos guerrilleros, que se han alzado contra el Estado, reclaman que éste reconozca la existencia de un conflicto y que les otorgue estatus de beligerancia. Muchos estudiosos consideran que en Colombia sí existe un conflicto y que es una necedad no reconocerlo.

Por su parte, los gobiernos de turno y muchos académicos no sólo se han negado a reconocer la existencia del conflicto, sino que consideran que la guerrilla, por sus acciones, son grupos terroristas que atentan contra las instituciones. De ahí que el lenguaje utilizado para referirse a ellos sea "bandoleros", "bandidos", "narcoterroristas".

En medio de la confrontación guerrilla-Fuerza Pública, aparece un tercer actor armado que ha complejizado aún más el conflicto: los paramilitares. Estos grupos (preparados desde las altas esferas del poder, como se ha demostrado) no han sido combatidos con la misma contundencia que a la guerrilla. De ahí que el lenguaje utilizado para referirse a ellos sea semánticamente menos "fuerte".

No es objetivo de este trabajo hacer un análisis del conflicto colombiano, sino mostrar la forma como algunos hechos se registran en ciertos medios, teniendo en cuenta tendencias ideológicas.

Texto noticioso que registra la marcha contra la guerrilla de las FARC

El Tiempo, 4 de febrero de 2008

Millones marcharon contra las Farc

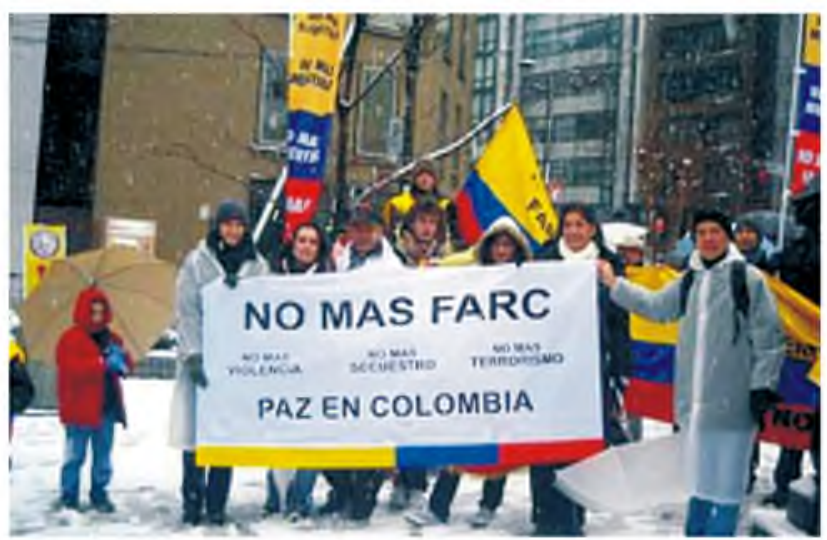

A pesar de las nevadas, colombianos marcharon en Tokio.
Una muchedumbre taponó las principales calles bogotanas con pancartas, pasacalles y pendones con arengas en favor de la libertad de los secuestrados en Colombia. Pasado el mediodía y en medio de un incesante flujo de gente en las calles de Bogotá, el general Rodolfo Palomino, comandante de la policía metropolitana, dijo que al menos dos millones de personas marcharon en esta capital. "Nuestra voz de gratitud a todos los colombianos que hoy han expresado con dignidad y fortaleza el rechazo al secuestro y a los secuestradores'", dijo el presidente Álvaro Uribe desde la ciudad de Valledupar. El vicepresidente Francisco Santos, al participar en la protesta en Bogotá, aseguró que si las Fuerzas Armadas Revolucionarias de Colombia, Farc, mantenían prácticas como el secuestro "van a continuar marginándose políticamente... la gente está hasta aquí", agregó, señalando con una mano el tope de su cabeza.

"¡Libertad, libertad!, No más Farc, No más secuestros", corearon cientos de miles de personas que se volcaron a las calles de 40 ciudades colombianas, que prácticamente se paralizó al mediodía, como habían previsto los jóvenes que organizaron la protesta a través de Internet y que pidieron que no sea capitalizada por ninguna organización política.

"Siento la pena de los familiares que tienen secuestrados pudriéndose vilmente en la selva (...), y quiero que todas las naciones del mundo se den cuenta que las Farc no son Colombia", dijo Myriam Forero, una jubilada del poder judicial que participó de una de las protestas en Bogotá.

En Bogotá, las marchas arrancaron desde diversos puntos de la capital hacia las 10 a.m. y desembocaron en la Plaza de Bolívar, en el corazón histórico de la ciudad, colmada por miles de personas con camisetas blancas. Las congregaciones también formaron ríos humanos de color blanco en Cali, Medellín, Barranquilla y las principales ciudades colombianas, según imágenes de televisión. En la plaza de Bolívar de Bogotá fueron colocadas más de 700 sillas vacías en representación de los secuestrados que se estima tienen las Farc.

\section{Uribe agradece multitudinaria participación}

Desde Valledupar, el presidente Álvaro Uribe dijo que los colombianos, en el país y en el exterior, rechazaron contundentemente la violencia y los secuestros de las Farc con su masiva asistencia a las movilizaciones. "Nuestra voz de gratitud a todos los colombianos que hoy han expresado con dignidad y con fortaleza el rechazo al secuestro y a los secuestradores", dijo Uribe. "Hacemos llegar nuestra voz de gratitud a los colombianos residentes en tantos países del mundo, que hoy se han unido con nosotros en esta cadena de energía espiritual contra el secuestro y contra el crimen", agregó. "Tolerancia es un sentimiento de un pueblo alegre y pluralista como es el pueblo colombiano; y respeto es la disposición de respetar la Constitución. Tolerancia es la disposición anímica y espiritual 
del pueblo colombiano; respeto a los principios de la convivencia entre los gobiernos, los estados y las naciones es el imperativo del ahora", indicó. "Todos quienes somos hoy responsables del Gobierno entendemos que esta marcha también es una exigencia del pueblo colombiano a nosotros, para que aportemos todas nuestras energías, todos nuestros esfuerzos por la erradicación definitiva del secuestro", puntualizó.

\section{Jornada en el exterior}

Más temprano se celebraron las movilizaciones de colombianos en ciudades europeas como Londres, París y Berlín. En otras capitales, como Madrid, será al atardecer, para coincidir con la hora de la marcha en Colombia. Las marchas en Tokio (Japón), Atlanta (E.U.), Sidney, Melbourne y Brisbane (Australia) resultaron ser el mejor termómetro de lo que vivirá la capital en contadas horas.

Ayer en la tarde, el grupo de Facebook que hace menos de un mes comenzó una convocatoria on line para marchar contra las Farc, cruzó el umbral de los 260.000 integrantes. En cerca de 160 ciudades de Colombia y buena parte del mundo, todos ellos se sumaron al lema: "No más secuestros. No más mentiras. No más muertes. No más Farc". "Esperamos que 44 millones de colombianos nos acompañen el día de la marcha, esperamos que el país entero vendrá a acompañarnos", dijo Cristina Lucena, de 24 años, una estudiante de ciencias políticas en Bogotá y una de las seis principales organizadoras de la jornada.

\section{De Atlanta a Pekín}

Hoy está previsto que la manifestación haga sentir su voz en sitios tan distantes como Nueva York, San José, Pekín, Tel Aviv y París. En esta última, el permiso de congregación fue cambiado a última hora a la plaza de Châtelet. En España, habrá concentraciones en Madrid, Barcelona, Bilbao, Valencia, San Sebastián, Oviedo, Salamanca, Islas Canarias y Málaga.

Mientras que los colombianos residentes en las ciudades alemanas de Hamburgo, Munich, Francfort y Oberhausen sincronizaron el inicio de su marcha con el de aquellas en Colombia, la colonia de Berlín decidió congregarse a las 12:30 del mediodía (6:30 a.m. en Colombia). La marcha de la capital alemana arrancará desde la Iglesia de la Conmemoración y se dirigirá a la embajada de Colombia. Allí se espera que acudan unos 2000 manifestantes.

En Venezuela, la marcha de hoy contará con la participación de organizaciones estudiantiles y no gubernamentales que se unieron al rechazo a las Farc. La coordinadora de 'No más Farc Caracas', Milagros Ramírez, dijo que la marcha partirá a las 9:30 a.m. desde la Plaza Brión de Chacaíto y llegará a la residencia del embajador de Colombia, Fernando Marín Valencia, ubicada en Campo alegre.

En la antesala a las casi 150 manifestaciones previstas para hoy en todo el mundo, cientos de marchantes salieron ayer a las calles de Tokio, Sidney, Melbourne y
Brisbane (Australia). Incluso, a ellos se les adelantaron sus compatriotas en Atlanta (E.U.), en donde se registró, el sábado a mediodía, la primera marcha.

\section{Más seguridad en la capital}

En Bogotá, más de un millón de estudiantes de colegios distritales no tendrá clases. Las medidas de seguridad fueron reforzadas desde el pasado viernes, cuando se pusieron nuevos puestos de control. La capital estará custodiada por 8.337 uniformados. En TransMilenio, donde se espera una alta afluencia de usuarios, se extremaron las precauciones. El comandante de la Policía de Bogotá, general Rodolfo Palomino, recordó que está prohibido el porte de armas, hasta las 6 p.m.

\section{En el país todo está listo para la jornada}

En cada ciudad se han tomado medidas diferentes para facilitar las marchas e, incluso, para protegerlas. En los departamentos del Eje Cafetero, la Octava Brigada del Ejército suspendió la vigencia de los permisos para el porte de armas, sin excepción. La medida rige desde la 6 de la tarde de ayer, hasta las 8:00 a.m. de mañana.

La misma medida rige para el departamento de Cundinamarca. Entre tanto, en Arauca, además de la restricción al porte de armas, se prohibió sacar basura a la calle, se restringió la movilización en bicicletas y se exigirá carnet para los celulares.

En Bucaramanga, por decisión de la Alcaldía, impera la ley seca desde la 6 de la tarde de ayer y se mantendrá hasta las 6 de la tarde de hoy. Durante ese mismo lapso están prohibidos los trasteos y el transporte de cilindros de gas.

En Medellín, la Alcaldía hizo un llamado para que los asistentes eviten el uso de camisetas con estampados para evitar cualquier roce.

En Cali tampoco hay restricciones especiales, pero la Policía destinó a 1.300 hombres, respaldados por un helicóptero, para custodiar a los ciudadanos que se movilicen hoy.

\section{Lo que el texto registra sobre la marcha} del 4 de febrero

1) Se muestra explícitamente que la movilización fue contra las FARC: el título, la fotografía y las voces que se pronuncian así lo señalan.

2) El texto muestra que la movilización contra las FARC fue muy nutrida. Las palabras y las expresiones denotan y connotan multitud de personas:

- $\quad$ "Millones marcharon contra las FARC".

- $\quad$ "Una muchedumbre taponó las principales calles bogotanas".

- "Incesante flujo de gente en las calles de Bogotá".

- "Dos millones de personas marcharon en esta capital".

- $\quad$ "Cientos de miles de personas que se volcaron a las calles".

- "Las congregaciones también formaron ríos humanos". 
- $\quad$ "En Bogotá, más de un millón de estudiantes de colegios distritales no tendrá clases".

3) El texto registra que la marcha se dio en casi toda Colombia, o por lo menos en sus principales ciudades: Bogotá, Medellín, Cali, Barranquilla, Bucaramanga, Valledupar.

4) El texto muestra que la marcha no sólo se dio en Colombia, sino también en otras partes del mundo: Tokio, Sidney, Atlanta, Tel Aviv, Islas Canarias, Francfort, etc.

5) El texto muestra que hubo unidad de rechazo contra las FARC. El color blanco simboliza esa unidad.

6) El texto muestra un gran despliegue y organización por parte de las Fuerzas Militares para garantizar la seguridad de los marchantes.

7) El diario muestra que el presidente del momento, Álvaro Uribe Vélez, agradece al pueblo por salir a marchar.

\section{Observaciones sobre el registro de esta marcha}

La forma como el diario El Tiempo registra la marcha contra la guerrilla de las FARC, merece unas reflexiones, no sólo por lo que dice, sino también por lo que oculta. He aquí estas observaciones:

1) En esta marcha también hubo voces contra los otros agentes del conflicto: paramilitares, Fuerzas Militares y grupos emergentes. Organizaciones no gubernamentales no sólo protestaron contra las FARC, sino también contra estos actores. No obstante, el diario no registra esas voces porque, al parecer, el objetivo es darle un golpe mediático a las FARC.

2) Se muestra que la marcha contra las FARC fue muy nutrida, lo cual fue cierto. Debe tenerse en cuenta que esta movilización tuvo un amplio despliegue propagandístico en todos los medios. Con eso se demuestra su gran poder de convocatoria.

3) El texto deja la sensación de que el mundo y el país se "paralizaron" ante el evento: en los lugares más recónditos, y "a pesar de las nevadas" (como lo señala el pie de foto), la gente salió a marchar contra las FARC. Se infiere que salir a marchar ese día era un deber "universal" y "patriótico".

4) En el texto se ve un gran despliegue de las Fuerzas Militares para garantizar la seguridad de los marchantes. Es una forma de mostrar que la política de Seguridad Democrática del Presidente Uribe (su programa bandera) sí funciona, pues no se registran incidentes. Sin embargo, en las marchas se presentaron disturbios que la prensa no registra.

5) Los partidos independientes y de oposición (entre ellos el Polo Democrático Alternativo, de izquierda) también salieron a marchar contra las FARC. Pero el diario no lo registra. Ese ocultamiento deliberado crea la sensación de que sólo los partidos seguidores del Presidente marcharon contra las FARC. No se menciona que los de izquierda también lo hicieron porque se busca aislarlos de la protesta contra las FARC, para que semánticamente se les asocie con ellos. Es una vieja práctica tendenciosa: mostrar, ocultando.

6) Pese a que los organizadores de la marcha (usuarios de Facebook) pidieron no "politizar" el evento, el diario muestra que la manifestación fue un triunfo político del presidente Álvaro Uribe. Se les da poco despliegue a los organizadores y se pone al mandatario como figura sobresaliente.

7) Interesante resulta la mención que se hace de la marcha en Venezuela, cuyo presidente del momento (Hugo Chávez) tenia diferencias ideológicas con el de Colombia. En el registro se les da prioridad a las organizaciones estudiantiles y no gubernamentales, con el fin de señalar implícitamente la "cercanía" de ese presidente con las FARC. En cambio, el rechazo a las FARC por parte de las organizaciones no gubernamentales en Colombia no se registra en el diario.

\section{Marcha del 6 de marzo}

contra los grupos paramilitares

Contexto socio-político en que se produce el texto noticioso de análisis

Los grupos paramilitares en Colombia han tenido como objetivo principal combatir a la guerrilla, no a la Fuerza Pública con la que han sostenido nexos muy cercanos. Sin embargo, las incursiones de estos grupos han dejado más víctimas en la población civil que en la guerrilla. De ahí que distintos sectores sociales y políticos convocaran a una marcha para el 6 de marzo en rechazo al accionar de estos grupos violentos, que han dejado miles de víctimas. Esta convocatoria no tuvo el mismo despliegue propagandístico en los medios de comunicación.

\section{Texto noticioso que registra la marcha contra los paramilitares}

El Tiempo, 6 de marzo de 2008

Miles de colombianos marcharon por las víctimas de la violencia en varias ciudades del pais

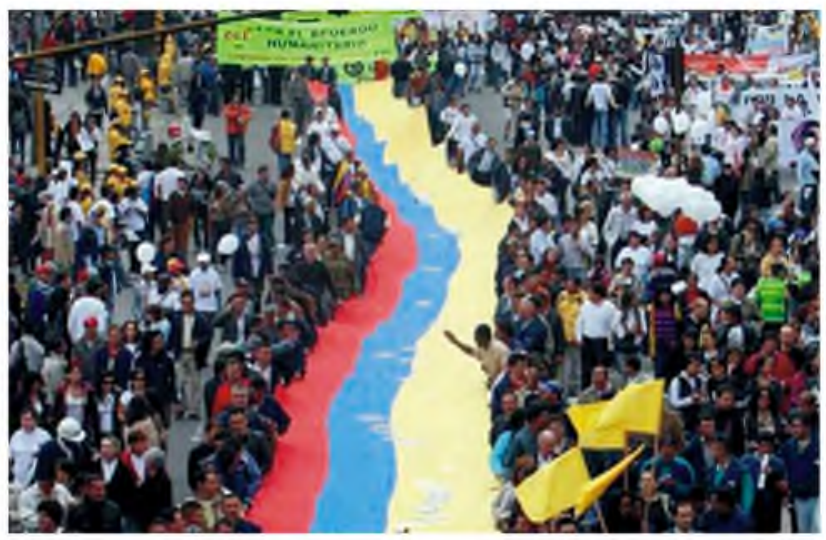

Así se vio la marcha de miles que recorrieron la carrera Séptima desde el Parque Nacional hacia la Plaza de Bolívar antes del mediodía. 
Por momentos la marcha pareció más una protesta política, pero por otros fue un gran encuentro cultural cuyo tema era la violencia. Las mujeres fueron protagonistas. Sobre la carrera Séptima de Bogotá, paso obligado de muchos para entrar a la Plaza de Bolívar, donde tuvo lugar la mayor concentración de manifestantes, una larga tira de fotos y recortes de periódicos que recogían la larga historia de masacres de los paramilitares, simbolizó el mensaje de la movilización.

Al igual que en la marcha del pasado 4 de febrero contra las Farc, se vieron miles de camisetas blancas. Pero, como lo había anunciado el Movimiento de Víctimas de Crímenes de Estado, que organizó la jornada, se sumaron otros colores asociados a la historia de la violencia en Colombia. Se vieron el amarillo de la Unión Patriótica, el negro de las fotos con los rostros de los desaparecidos y secuestrados, el violeta del luto de algunas viudas y desplazadas y el rojo de algunos sindicatos y grupos de universitarios. Estos últimos, más empeñados en atacar con sus consignas al Gobierno que en rendir homenaje a las víctimas. Una de las mujeres que desfiló llevó un armazón en madera sobre el cual reposaban unos huesos que, dijo, representaban la forma en que se encontraban los desaparecidos en las fosas cavadas por los paramilitares.

\section{Ellas, por miles}

La cantidad de mujeres que marcharon ayer, no solo en Bogotá sino en varias ciudades del país, dejó al descubierto una de las más crudas realidades del conflicto armado. Ellas son, como lo ha constatado la Comisión de Reparación y Reconciliación (CNRR), las que han cargado con el peso de la violencia. "En nombre de la paz hacen la guerra. Farc, Auc, iqué vergüenza!", decía una pancarta que llevaban las integrantes de la Red Nacional de Mujeres Desplazadas. Los organizadores de la marcha no fueron los primeros en llegar a la Plaza de Bolívar. Cuando avanzaban sobre la carrera Séptima se les 'colaron' por la avenida 19 y la avenida 13 otras marchas de profesores, funcionarios de entidades como el Sena, estudiantes universitarios y desplazados. A Iván Cepeda, el vocero del Movimiento de Víctimas, esto lo emocionó tanto que dijo que se trataba de "un verdadero golpe de opinión para el Gobierno". Ahí la marcha volvió a parecer más política. Pero entre la multitud, dos mujeres de rostro triste cargaban una cartulina con la foto de Jorge Enrique Vargas, un conductor de 33 años que el 29 de abril del 2003 fue retenido por las autodefensas en San Martín (Meta).

Muchos de los que llegaron a la Plaza de Bolívar pisaron sin darse cuenta centenares de siluetas de hombres y mujeres hechas con cinta blanca. Cada una representaba a un desaparecido o a una víctima de la violencia. Como la que recordaba a Ángela María Murillo, desaparecida en la toma del Palacio de Justicia, en noviembre de 1985.

\section{Partidos se hicieron sentir}

Cerca del mediodía, el alcalde de Bogotá, Samuel Moreno, marchó desde el céntrico parque Santander acompañado de varios de sus secretarios de despacho. "Este es un nuevo llamado a la tolerancia, a la paz, a la convivencia y un mensaje para solidarizarnos con las familias de los desaparecidos, los asesinados, los que están secuestrados, con quienes hoy infortunadamente no están con sus familias", dijo. Al lado, el senador del Polo Gustavo Petro marchaba con una pancarta en la que se veía al caudillo liberal Jorge Eliécer Gaitán, al que calificó como "una de las grandes víctimas de la violencia de Estado". Muy cerca iba el ex gobernador del Valle Angelino Garzón, quien calificó la movilización como una muestra de que la sociedad rechaza la violencia independientemente de su origen. En medio del asedio de los medios, el senador liberal Juan Fernando Cristo aseguró que la participación de la gente servía para poner a las víctimas "en el lugar de privilegio que les corresponde".

Ni la lluvia, ni el grupo de jóvenes que pasadas las 3 de la tarde intentaron alterar la tranquilidad sobre la calle 17 con carrera Séptima agrediendo a miembros de la Fuerza Pública, lograron empañar la marcha pacífica por las víctimas. Si bien no fue tan multitudinaria como la que se hizo contra las Farc, fue conmovedora en todas las ciudades donde se solidarizaron con quienes han sufrido el conflicto.

\section{Cuatro testimonios de la marcha}

\section{Flor Gallego, campesina de Antioquia}

"La Esperanza -en el Carmen de Viboral, Antioquia- era una vereda tranquila, pero el 21 de junio de 1996 llegó Ramón Isaza apoyado por militares y comenzó a llevarse a la gente. Se llevaron a mi esposo, a dos hermanos, a una prima.... a 15 familiares. Le hemos reclamado a todo el mundo y logramos que Isaza nos recibiera, pero dijo que ellos no enterraban a la gente, sino que la tiraban al río".

\section{María Elena Barrera, madre de militante de la UP}

"A mi único hijo, José Domingo Carrero Barrera, lo secuestraron, lo torturaron y lo asesinaron el 7 de abril de 1992, cuando tenía 26 años. Estudiaba ingeniería de sistemas y era de la UP, ese fue su delito. A los cuatro días de su desaparición encontramos su cuerpo: estaba con la cara tapada, las manos atadas a la espalda y los pies amarrados. Tenía dos tiros en la cabeza" (Bucaramanga).

\section{Deisy quiere volver a ver a su hija}

"Un grupo de hombres con armas llegaron a la casa de mi hija en un carro, preguntando por ella y su marido. Él escapó, pero a ella la embarcaron en el carro. Eso pasó el 4 de abril del año 2002 en Puente Bomba (Riohacha), donde vivía mi hija Zenith del Carmen. Desde entonces, no sé nada de ella y eso me ha mantenido angustiada todos estos años. Pido a quienes la tienen que le respeten su vida". 
Nancy Jiménez perdió a su hija en Buenaventura

"Mi hija Katherine Soto sigue viva, así haya tenido que sepultarla en agosto. Yo no necesito dinero, solo justicia. Ella, de 21 años, estudiante de Licenciatura en Ciencias Sociales, salió en la mañana del primero de agosto para la reserva de San Cipriano, en Buenaventura. Después recibí una llamada del Ejército. Me dijeron que murió en un enfrentamiento", Nancy Jiménez.

Lo que el texto registra sobre la marcha

del 6 de marzo

1) En el titular se registra que la marcha es contra las víctimas de la violencia.

2) Se muestra que la marcha fue más un encuentro cultural "cuyo tema era la violencia".

3) En el texto se hace énfasis en las víctimas, no en el victimario (paramilitares).

4) Se muestra que la marcha contra los paramilitares no fue muy nutrida.

5) El texto muestra que la marcha fue más una protesta política.

6) Se registra que la marcha sólo se realizó en Bogotá.

7) Se registra que sólo el Polo Democrático Alternativo marchó contra los paramilitares.

8) El texto registra que los manifestantes agredieron a la Fuerza Pública.

9) Los temas de la marcha ya hacían parte de la historia del país.

\section{Observaciones sobre el registro de esta marcha}

1) En el título no se registra que la marcha fuera contra los paramilitares, sino contra la violencia. Para minimizar que la marcha haya sido contra estos grupos, se introducen otros actores del conflicto: FARC y Fuerza Pública. Se infiere que la marcha fue contra la violencia en general, "independientemente de su origen" (como señala un dirigente político en el texto), y no contra un grupo ideológicamente cercano al gobierno y al Establecimiento.

2) En este registro se hace énfasis en las víctimas, no en el victimario (paramilitares). Se esconde el agente que realiza la acción para resaltar el paciente que la recibe. Para entender cómo funciona semánticamente esto, veámoslo en estos titulares inventados: Los paramilitares asesinaron a personas inocentes y Personas inocentes fueron asesinadas por los paramilitares. En los dos "titulares" hay diferencias semánticas: mientras en el primero (voz activa) se enfatiza en el victimario (paramilitares), en el segundo (voz pasiva) se prioriza a la víctima (personas inocentes). Incluso, en este último se puede esconder el agentivo: Personas inocentes fueron asesinadas.

3) El texto muestra que la marcha contra los paramilitares no fue muy nutrida (lo cual fue cierto, pues no tuvo el mismo eco en los medios informativos). El título mismo dice que fueron miles y no millones. Eso demuestra también que los medios, de acuerdo a sus tendencias ideoló- gicas, escogen los referentes que quieren mostrar u ocultar.

4) Como una forma de minimizar la movilización, se muestra que la marcha sólo se realizó en Bogotá, lo que no fue cierto. En otras ciudades del país y en muchos lugares del mundo también se marchó.

5) El texto señala que en esta marcha no hubo unidad como en la anterior, pues mientras en aquélla hubo "ríos humanos de color blanco", en ésta sólo hubo "miles de camisetas blancas" a las que se sumaron "otros colores".

6) No se registra que algunos partidos gobiernistas también marcharon contra los paramilitares. Ese ocultamiento deliberado tiene el propósito de mostrar que únicamente el Polo Democrático Alternativo (de izquierda) marchó contra ellos. La intención es que el lector asocie inconscientemente este partido con las FARC, grupo opositor de los paramilitares.

7) Al registrar que hubo agresión contra la Fuerza Pública (situación que según el medio no se presentó en la marcha anterior) se tiene la intención de deslegitimar la marcha.

8) Al señalar que los temas de la marcha ya hacían parte de la historia del país, se busca mostrar que son "refritos" inundados de lugares comunes que no tiene sentido recordar en una marcha: desaparecidos del Palacio de Justicia (1985), desaparecidos de la Unión Patriótica (partido de izquierda exterminado a finales de los ochenta y comienzos de los noventa), muerte de Jorge Eliécer Gaitán (dirigente liberal asesinado en 1948).

\section{Resultados}

En el análisis de los dos textos noticiosos puede comprobarse una marcada tendencia ideológica del diario en el enfoque de los dos acontecimientos. Se evidencia que busca maximizar la marcha contra las FARC y, a su vez, minimizar la que se realizó contra los paramilitares. Bien es sabido que la prensa en Colombia ha sido gobiernista desde siempre, especialmente el diario El Tiempo. De ahí que el registro de los dos hechos tenga una orientación tan distinta.

Estos textos, que se muestran en la superficie como expositivo-informativos, organizan la cadena discursiva de manera que en el fondo funcione una modalidad argumentativa que busca, por un lado, legitimar la marcha contra las FARC (grupo que se ha alzado en armas contra el Estado y el Establecimiento) y, por otro, minimizar la marcha que se realiza contra los paramilitares (grupos que han actuado en connivencia con el Estado y el Establecimiento). En el siguiente cuadro se presentan las afirmaciones y los argumentos implícitos que demuestran el funcionamiento de la argumentación: 


\begin{tabular}{|c|c|c|}
\hline AFIRMACION & CONECTOR & ARGUMENT \\
\hline $\begin{array}{l}\text { Las FARC no tienen respaldo político en la comunidad } \\
\text { nacional e internacional... }\end{array}$ & ...porque & ...millones marcharon contra ellas. \\
\hline Las FARC son el grupo más detestado por la sociedad... & ...porque & $\begin{array}{l}\text {... en la marcha contra ella no hubo voces } \\
\text { contra los otros actores. }\end{array}$ \\
\hline $\begin{array}{l}\text { Los partidos de izquierda y las organizaciones no } \\
\text { gubernamentales no marcharon contra las FARC... }\end{array}$ & ...porque & ...están de acuerdo con sus acciones. \\
\hline $\begin{array}{l}\text { Las personas se identifican más con los grupos } \\
\text { paramlltares... }\end{array}$ & ...porque & $\begin{array}{l}\text {...en la marcha que se convocó contra ellos } \\
\text { asistió poca gente. }\end{array}$ \\
\hline $\begin{array}{l}\text { La gente reconoce que los paramilitares no son los únicos } \\
\text { actores del conflicto... }\end{array}$ & ...porque & $\begin{array}{l}\text {...en la marcha que se convocó contra ellos } \\
\text { también había pancartas contra las FARC y } \\
\text { las Fuerzas Militares. }\end{array}$ \\
\hline $\begin{array}{l}\text { La marcha contra los paramilitares fue un refrito de lugares } \\
\text { comunes... }\end{array}$ & ...porque & $\begin{array}{l}\text {...había consignas contra hechos que ya } \\
\text { pasaron a la historia. }\end{array}$ \\
\hline $\begin{array}{l}\text { La marcha contra los paramilitares fue una protesta } \\
\text { política... }\end{array}$ & ...porque & ...se lanzaron arengas contra el gobierno. \\
\hline $\begin{array}{l}\text { Los partidos de izquierda marcharon contra los } \\
\text { paramllltares... }\end{array}$ & ...porque & $\begin{array}{l}\text {...son el lado opuesto de las FARC, } \\
\text { organización más cercana su ideología. }\end{array}$ \\
\hline $\begin{array}{l}\text { La marcha contra los paramilitares fue de poca } \\
\text { importancia... }\end{array}$ & ...porque & $\begin{array}{l}\text {...sólo se marchó en Bogotá y en ninguna otra } \\
\text { parte del mundo. }\end{array}$ \\
\hline $\begin{array}{l}\text { Los partidos gobiernistas no marcharon contra los } \\
\text { paramllltares... }\end{array}$ & ...porque & $\begin{array}{l}\text {...la marcha estaba infiltrada por la guerrilla } \\
\text { de las FARC. }\end{array}$ \\
\hline
\end{tabular}

Es importante señalar que este análisis no se hace a los registros de un diario cualquiera o amarillista, sino al de mayor circulación en Colombia. Al diario que ha realizado foros y seminarios sobre libertad de expresión, sobre el papel de la prensa en el conflicto armado, sobre el derecho de las personas a estar verazmente informadas; al diario que tiene un Defensor del Lector para garantizar la imparcialidad y el equilibrio en el manejo de la información. Esto valida aún más el análisis, pues deja al descubierto que los grandes medios de comunicación esconden intereses y perfilan la información hacia ellos.

Por lo tanto, mostrar que en un texto noticiosoinformativo puede funcionar todo un proceso de argumentación en el nivel más profundo, lo que deja en evidencia es que existe una estrecha relación entre medios de comunicación, poder y política. En el caso que nos ocupa, se ha demostrado que el discurso informativo de la prensa, por ser una estructura generada en instituciones inmersas en condiciones de poder y dominación, se orienta hacia intereses afines a su ideología. En este sentido, el lenguaje que se usa en el discurso informativo de la prensa no sólo puede ser ideológico, sino que también puede ideologizar cuando se realizan acciones estratégicas encubiertas orientadas a la manipulación y la desinformación.

Para entender que los textos noticiosos publicados provienen de instituciones inmersas en condiciones de poder, basta decir que el diario El Tiempo, de la Casa Editorial El Tiempo, es de propiedad de la familia Santos y del banquero que controla casi todo el sistema financiero en Colombia. Además, en el momento en que se publican los textos, el vicepresidente de
Colombia, Francisco Santos, era accionista del diario. Esto demuestra la estrecha conexión entre medios de comunicación, poder y política. Aún más: se demuestra que el poder es uno solo y que se diversifica en política, medios de comunicación y economía, lo que confirma la tesis de que actualmente los medios de comunicación no son un contrapoder, sino la expresión natural de los demás poderes.

Así las cosas, podemos afirmar que quien lee la prensa, si no tiene herramientas cognitivas e intelectuales para detectar el engaño, puede ser manipulado a través de mecanismos discursivos. En una investigación de esta naturaleza es indispensable la formulación de preguntas como: $¿ E l$ discurso informativo de la prensa, debido a sus condiciones de producción, es ideológico e ideologizante? ¿Qué papel deben desempeñar los medios informativos en la vida cotidiana, en los procesos electorales, en las guerras y en los conflictos? ¿Pueden y deben ser imparciales, equilibrados, objetivos y neutrales los medios informativos? ¿Es tarea del Análisis Crítico del Discurso crear herramientas para contrarrestar la manipulación que se puede ejercer desde el discurso informativo de la prensa?

Estas preguntas invitan a la discusión, que debe ser abierta a todas las posibilidades de análisis discursivo. Este trabajo no agota la discusión sobre este tipo de discurso, teniendo en cuenta que el corpus analizado es bastante limitado. Sin embargo, el análisis crítico del discurso informativo de la prensa es una investigación que se proyecta con mayor fuerza en los últimos años, en un mundo que se mueve vertiginosamente alrededor de la información. 


\section{Referencias Bibliográficas}

Charaudeau, P. (2003). Fl discurso de la información. La construcción del espejo social. Barcelona: Gedisa.

Costa, R. y Mozejko, D. (2001). El discurso como práctica. Lugares desde donde se escribe la historia. Buenos Aires: Ediciones Homo Sapiens.

Habermas, J. (1997). Teoría de la acción comunicativa: complementos y estudios previos. Madrid: Cátedra.

Meyer, M. (2003). "Entre la teoría, el método y la política: la ubicación de los enfoques relacionados con el ACD". En Wodak \& Meyer (Comp.), Métodos de análisis crítico del discurso (pp. 35-59). Barcelona: Gedisa.

Ramonet, I. (2004). "La prensa es un poder que no tiene contrapoder". Diario El Tiempo, 2/09/04 [en línea]. Disponible en: http://www.eltiempo.com/archivo/documento/MAM-1546548

Rey, G. (2000). "Más allá de las disculpas". Diario El Tiempo, 24/12/00 [en línea]. Disponible en:

http://www.eltiempo.com/archivo/documento/MAM-1278665

Van Dijk, T. (1999). "El análisis crítico del discurso". [en línea]. Disponible en:

http://www.discursos.org/oldarticles/El\%20an\%E1lisis\%20cr\%ED tico\%20del\%20discurso.pdf

Van Dijk, T. (2005). El discurso como interacción en la sociedad. Barcelona: Gedisa.

Wodak, R. (2003). "De qué trata el análisis crítico del discurso (ACD). Resumen de su historia, sus conceptos fundamentales y sus desarrollos". En Wodak \& Meyer (Comp.), Métodos de análisis crítico del discurso (pp. 17-34). Barcelona: Gedisa. 